\title{
Relevância do método Pilates nas alterações musculoesqueléticas na terceira idade
}

\author{
Relevance of the Pilates method in musculoskeletal changes in the elderly
}

Relevancia del método Pilates en los cambios musculoesqueléticos en el anciano

\section{Resumo}

O envelhecimento é um processo fisiológico, que desenvolve alterações que ocorrem no corpo, como por exemplo: diminuição da imunidade, da propriocepção, do equilíbrio, da capacidade respiratória, podendo levar ao isolamento social, além de muitos idosos possuírem uma ou mais doenças crônicas. Tendo em vista os benefícios do método Pilates, desenvolvido por Joseph Pilates, melhorando ou mantendo as capacidades funcionais dos idosos, ele também possui inúmeras possibilidades de exercícios, podendo se adequar de acordo com a necessidade de cada um dos idosos. O objetivo desta Revisão de Literatura é enfatizar os benefícios proporcionados pelo método Pilates, para promover saúde, melhorando a qualidade de vida dos idosos e melhorando, ou mantendo as capacidades funcionais. O estudo é uma Revisão de Literatura de caráter Descritivo e Quantitativo, pesquisado em bases de dados, como: Scientific Electronic Library (SCIELO); Publisher Medline (PubMed) e Google Acadêmico, com os descritores "Idoso"; "Pilates"; "Envelhecimento". Portanto, o método promove o fortalecimento da musculatura estabilizadora da coluna, utilizando poucas repetições de movimentos, proporcionando independência e autonomia aos idosos, reduzindo o número de lesões, e proporcionando outros benefícios funcionais.

Palavras-chave: Pilates; Idoso; Fisiologia.

\begin{abstract}
Aging is a physiological process that develops changes that commonly occur in the body, such as: decreased immunity, proprioception, balance, respiratory capacity, which can lead to social isolation, in addition to the fact that many elderly people have one or more chronic diseases . In view of the benefits of the Pilates method, developed by Joseph Pilates, improving or maintaining the functional abilities of the elderly, it also has numerous exercise possibilities, which can be adapted according to the needs of each elderly person. The purpose of this Literature Review is to emphasize the benefits provided by the Pilates method to promote health, improving the quality of life of the elderly and improving or maintaining functional abilities. The study is a Descriptive and Quantitative Literature Review, searched in databases such as: Scientific Electronic Library (SCIELO); Publisher Medline (PubMed) and Google Scholar, with the descriptors "Elderly"; "Pilates"; "Aging". Therefore, the method promotes the strengthening of the spinal stabilizing musculature, using few repetitions of movements, providing independence and autonomy to the elderly, reducing the number of injuries, and providing other functional benefits.
\end{abstract}

Keywords: Pilates; Old man; Physiology.

\section{Resumen}

El envejecimiento es un proceso fisiológico que desarrolla cambios que comúnmente ocurren en el cuerpo, tales como: disminución de la inmunidad, propiocepción, equilibrio, capacidad respiratoria, que puede llevar al aislamiento social, además de que muchos ancianos padecen una o más enfermedades crónicas. . A la vista de los beneficios del método Pilates, desarrollado por Joseph Pilates, mejorando o manteniendo las capacidades funcionales de las personas mayores, también cuenta con numerosas posibilidades de ejercicio, que se pueden adaptar según las necesidades de cada anciano. El propósito de esta Revisión de la literatura es enfatizar los beneficios que brinda el método Pilates para promover la salud, mejorar la calidad de vida de las personas mayores y mejorar o mantener las capacidades funcionales. El estudio es una Revisión de Literatura Descriptiva y Cuantitativa, buscada en bases de datos como: Biblioteca Electrónica Científica (SCIELO); Publisher Medline (PubMed) y Google Scholar, con los descriptores 
"Ancianos"; "Pilates"; "Envejecimiento". Por lo tanto, el método promueve el fortalecimiento de la musculatura estabilizadora de la columna, utilizando pocas repeticiones de movimientos, brindando independencia y autonomía a las personas mayores, reduciendo el número de lesiones y brindando otros beneficios funcionales.

Palabras clave: Pilates; Anciano; Fisiología.

\section{Introdução}

O envelhecimento é um processo fisiológico normal que diminui as funções fisiológicas, como, por exemplo: diminuição da imunidade, da propriocepção, do equilíbrio, da capacidade respiratória, que pode levar ao isolamento social. Contudo, para amenizar essas perdas, o exercício físico atua diminuindo as incapacidades que irão proporcionar uma melhora ou permanência das capacidades funcionais fisiológicas, além de auxiliar os idosos a manterem a propriocepção, o equilíbrio, a força muscular, a flexibilidade, as atividades de vida diárias (AVDs) e reduzir as doenças crônicas (Matsudo, 2001).

E por esse motivo, é comum na terceira idade que muitos idosos possuam uma ou mais doenças crônicas, como: artrite, artrose, sarcopenia, além da perda das capacidades funcionais devido a idade avançada, embora todos esses fatores e muitos outros estejam ligados tanto a fatores biológicos, como psicossociais e ambientais (Verderi, 2002).

No entanto, o método Pilates pode trazer benefícios para os idosos ao atuar amenizando as diminuições das capacidades funcionais que são provocadas pelo envelhecimento fisiológico normal e pelas patologias associadas, e com isso ocasiona o melhoramento cardiorrespiratório, da circulação sanguínea o aumento da resistência, da flexibilidade, do equilíbrio postural, da propriocepção, além de proporcionar maior independência ao idoso, por melhorar a coordenação motora e a consciência corporal pela eficácia da realização dos exercícios que fortalecem a musculatura estabilizadora da coluna e influencia na calcificação óssea (Gallagher \& Kryzanowska, 2000).

Desse modo, o método vem oferecer o aumento da percepção dos movimentos, que vão contribuir com o equilíbrio e a consciência corporal, ajudando a diminuir o estresse, o número de quedas, e possibilitando qualidade de vida, através dos seis princípios básicos do Pilates, que são: concentração, controle, centralização, fluidez, precisão e respiração. Joseph Pilates visa o fortalecimento de todos os grupos musculares, com ênfase nos músculos estabilizadores da coluna e a melhora da capacidade respiratória (Martins, 2013).

\section{Metodologia}

O estudo é caracterizado por uma revisão bibliográfica, descritiva e exploratória de abordagem qualitativa. Tendo como base para a discussão teórica, artigos científicos (Pereira et al., 2018).

O levantamento de dados foi realizado a partir de pesquisas encontradas nas plataformas digitais: Scientific Eletronic Library Online (SciELO), Publisher Medline (PubMed) e Google Acadêmico, onde os descritores utilizados foram: idoso, Pilates e envelhecimento. E o objetivo deste artigo é demonstrar a relevância que o método Pilates traz diante das alterações musculoesqueléticas, que ocorrem durante o processo de envelhecimento.

\section{Discussão}

\section{Envelhecimento}

O envelhecimento é um processo fisiológico normal, que com o passar dos anos diminui as funções fisiológicas, como, por exemplo: diminuição da imunidade, da propriocepção, do equilíbrio, da capacidade respiratória, que pode levar ao isolamento social, e por isso é comum que no processo de envelhecimento muitos idosos tenham uma ou mais doenças crônicas, como: artrite, artrose, sarcopenia, além da perda das capacidades funcionais, devido a idade avançada, embora todos esses fatores e muitos outros estejam ligados tanto a fatores biológicos, como psicossociais e ambientais, então para promover 
uma melhora funcional, é preciso enfatizar como é prejudicial o sedentarismo na terceira idade, e através do processo de envelhecimento as capacidades físicas e funcionais são reduzidas, o que prejudica na realização das AVDs. Dentre as principais capacidades que são reduzidas com o processo de envelhecimento, está o equilíbrio postural que é uma capacidade muito complexa devido a integração dos processos sensório-motor dinâmico, que está ligado a recepção e a interação dos estímulos sensoriais, e na execução dos movimentos, controlando assim a base de sustentação dos MMII (Lopes; Siedler, 2007).

Assim como o equilíbrio, a força muscular é um fator significante para a realização das atividades diárias. Com isso, é definida como a capacidade máxima que um indivíduo possui para poder vencer uma resistência, e por isso, a força muscular auxilia o músculo a aumentar os níveis de força, que vai de acordo com o tipo de ação. Portanto, a redução de força muscular, reduz as respostas motoras, aumentando o risco de lesão e queda, e outra capacidade fundamental que com o envelhecimento vai se reduzindo é a flexibilidade, e é por isso que os exercícios promovidos pelo Pilates ajudam a aumentar a quantidade e a qualidade dos movimentos, que vão favorecer o alinhamento, consequentemente irá melhorar o ciclo de marcha, aumentando a mobilidade e diminuindo o risco de lesões (Miranda; Morais, 2009; Trevisol; Silva, 2009).

\section{Alterações musculoesqueléticas}

As alterações fisiológicas intrínsecas do processo de envelhecimento são sutis e não geram qualquer incapacidade na fase inicial. No entanto, conforme vão passando os anos, ocasionam níveis crescentes de limitações no desempenho das AVD'S (Sung; Chuang, 2010).

Os sistemas musculoesquelético e ósseo têm destaque no processo de envelhecimento, pois os músculos esqueléticos compõem a maior massa tecidual do corpo humano, com cerca de 50\% do peso corporal, razão pela qual merecem destaque e são muito importantes na homeostasia bioenergética, tanto em repouso quanto em exercício, além disso, é o principal local de transformação e armazenamento de energia, sendo o suporte primário dos sistemas pulmonar e cardiovascular (Hain; Ramaswamy; Hillman, 2002).

O tecido muscular é conhecido como um tecido de multiplicidade de movimentos, no qual o ser humano é capaz de realizar. A execução desses movimentos é controlada pelo sistema nervoso e diferem de acordo com as características particulares dos vários tipos de fibras musculares, que segundo o processo de neuroplasticidade, um mesmo músculo, ou grupo muscular, tem a capacidade de responder e adaptar-se a um movimento podendo ser de elevada coordenação, a um esforço curto e intenso, ou de atividade prolongada (Sherwoor, 2010).

As alterações fisiológicas próprias do processo de envelhecimento podem levar a desenvolver uma maior fraqueza muscular, atrofia e a sarcopenia, que pode variar de acordo com cada idoso e se acentua mais em membros inferiores. Assim como outras alterações que vão surgir com o envelhecimento, como as endócrinas, nutricionais, mitocondriais, genéticas e comportamentais, aumentando o sedentarismo (Ralston, 2010). Além dos fatores fisiológicos do processo de envelhecimento, existem os fatores ambientais que afetam de forma direta a população idosa, fatores como: alimentação, exercícios, socioeconômico, familiar (Clarke, 2008).

Com o aumento da idade, as alterações ósseas e musculares tornam-se interdependentes, resultando em fragilidade óssea. Consequentemente, os músculos que dão sustentação ao corpo estão mais limitados, o que aumenta o risco de quedas e a sua consequência mais temida, as fraturas, porque todas as alterações estruturais e funcionais que ocorrem no sistema circulatório, decorrentes do processo natural de envelhecimento, atuam no mecanismo adaptativo compensatório diante às situações de sobrecarga (Chaudhary; El-Sikhry, 2011).

Com o avanço da idade, os déficits começam a repercutir de forma negativa nas funções celulares, em principal, nas células nervosas e da glia, o que torna mais difícil a neurogênese, plasticidade, condução e a transmissão dos impulsos 
nervosos, fazendo com que se tenha déficits consideráveis tanto no equilíbrio estático, quanto no dinâmico (NavehBenjamin,2007; Bear 2002).

Com o avanço da idade, a perda muscular é progressiva, e há uma significante perda na proporção de fibras musculares de contração rápida, as anaeróbicas, em comparação com as fibras de contração lenta, as aeróbicas. E devido a fraqueza muscular que ocorre de forma progressiva, os idosos tem a tendência de adotar posturas viciosas e compensatórias, que provocam um agravamento crescente das estruturas do aparelho locomotor, levando à alteração da marcha e a uma lentificação e perda de equilíbrio (Horak, 2006; Davies, 2001).

\section{Influência do Envelhecimento na Postura do Idoso}

A definição da palavra postura pode ser entendida como a maneira com que o indivíduo sustenta o seu corpo, podendo ter influência de fatores genéticos e emocionais. Para manter o corpo em posição estática, necessita-se de constante equilíbrio, levando em consideração a oscilação corporal, com o auxílio da ação da gravidade, a inconstância que aparece, é decorrente da ativação dos reflexos de estiramento e da força dos músculos antigravitacionais, que exercem um impulso contra a força de atração (Schwertner, 2007).

Gasparotto, et al (2012), relata que a postura do corpo pode se modificar com o passar dos anos, principalmente na terceira idade, sendo afetada principalmente pelos hábitos posturais incorretos adotados no cotidiano, com o avanço da idade, a inatividade do corpo propiciada pelo sedentarismo, diminui a capacidade muscular de sustentação da estrutura física (Figura 1), provocando uma acentuação das curvas vertebrais, frequentes no envelhecimento.

Figura 1 - Modificação da curvatura vertebral em decorrência da idade.

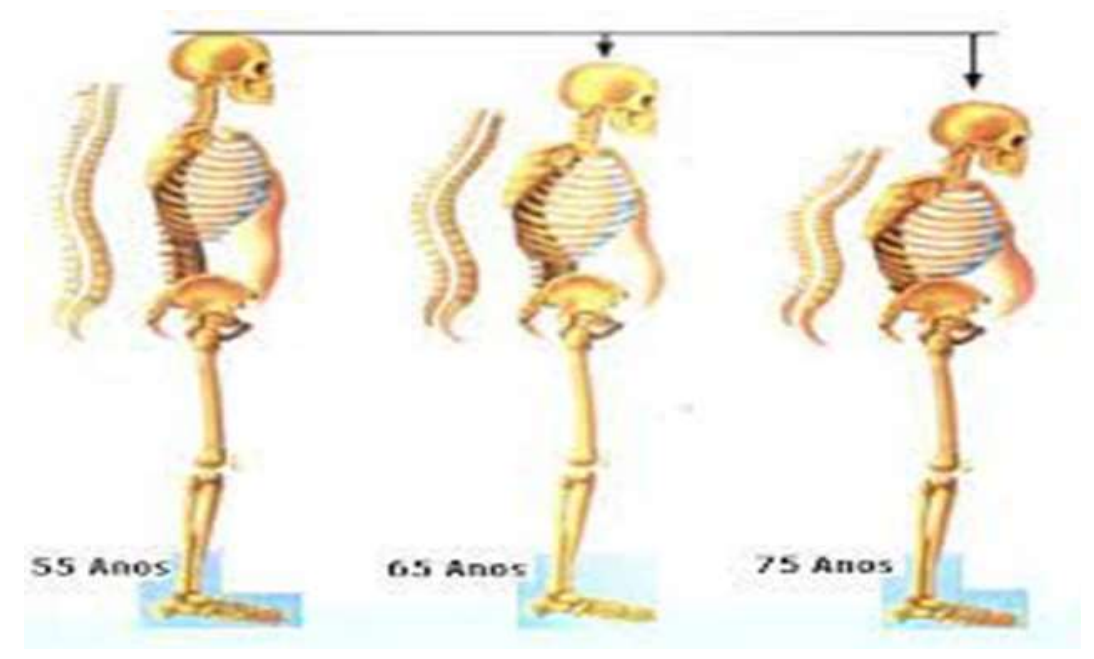

Fonte: http://www.ergonomia.ufpr.br/aulaposergo.pdf

A principal modificação decorrente do envelhecimento é a alteração postural dos idosos, uma vez que o comportamento da coluna vertebral e o centro da gravidade a partir dos 60 anos começam a apresentar alterações no equilíbrio, devido ao aumento da cifose torácica, redução da lordose lombar e anteriorização do tronco (Marques, 2012; Neto, 2004).

Ter conhecimento sobre as mudanças musculoesqueléticas provocadas pelo processo de envelhecimento e suas implicações funcionais, proporciona aos fisioterapeutas suporte para realizar uma anamnese mais eficiente, prevenir e tratar essas alterações, podendo se utilizar de recursos como o método Pilates, que tem como um dos objetivos minimizar os efeitos deletérios das disfunções cinésio-funcionais, promovendo liberdade funcional, melhorando a autoestima, diminuindo risco de quedas, fortalecendo e alongando toda a musculatura corporal, gerando consciência corporal e melhorando a qualidade de vida 
da terceira idade facilitando a realização das atividades de vida diária (Carvalho, 2011).

\section{História do Método Pilates}

Em 1883, na Alemanha, nasceu Joseph Pilates. Na sua infância sofria de asma, febre reumática e raquitismo. Autodidata, introduziu seus conhecimentos em Medicina Tradicional Chinesa, Anatomia e Fisiologia, onde suas influências se deram através das artes marciais e yoga. Com a chegada da Primeira Guerra Mundial, atuou como enfermeiro, auxiliando na recuperação dos feridos, começou a treinar os internos ensinando os exercícios que produziu a partir das molas das camas. Iniciou a tonificação muscular dos pacientes (soldados feridos) e desenvolveu aparelhos que são utilizados até hoje, como: cadillac, spine corrector, reformer, small barrel, dentre outros acessórios, e foi através das experiências adquiridas nesse tempo e o conhecimento de outras técnicas, que ele criou a base do seu método (Juliano e Bernardes, 2014).

Através disso, Joseph desenvolveu o método que consiste em seis princípios, que são: respiração, concentração, controle, centralização, fluidez e precisão, que proporcionam o aumento da força dos músculos centrais do corpo, aumento da amplitude dos movimentos (ADM), a flexibilidade natural da coluna, consciência corporal. Em 1918, seu trabalho ganhou destaque devido a uma epidemia que levou a óbito inúmeros ingleses, com exceção dos internos que estavam sob o seu treinamento, e foi onde se notou que esses internos tiveram a saúde beneficiada através dos exercícios, mesmo que ainda não tivesse comprovação científica. Contudo, ao final da guerra, de volta a Alemanha, Joseph Pilates conheceu Rudolf Von, que inseriu os princípios do Pilates a sua técnica corporal, e aos 46 anos, em 1926, mudou-se para os Estados Unidos onde fundou em Nova York, o seu primeiro estúdio, então foi a partir desse momento que o Pilates ganhou destaque entre os bailarinos da época, que procuravam Joseph Pilates para tratar lesões. No entanto, Joseph faleceu aos 87 anos, ao tentar salvar seus equipamentos em um incêndio onde inalou gases tóxicos em quantidades excessivas (Panelli; Marco, 2016).

\section{Princípios básicos do pilates}

Respiração: deve ser realizada em toda a execução dos movimentos, tendo como regra a inspiração no momento de preparação para realizar o movimento e a expiração na execução do movimento. (Muscolino \& Cipriani, 2004).

Concentração: é importante para ocorrer a realização dos movimentos que exigem atenção voltada para todo o corpo, para desenvolver os movimentos com a máxima perfeição, a atenção favorece o aprendizado motor. (Muscolino \& Cipriani, 2004).

Controle: é a consciência dos movimentos realizados pelo corpo. (Muscolino \& Cipriani, 2004).

Precisão: é a coordenação dos movimentos realizados com perfeição, possuir controle sobre o corpo e realizar movimentos precisos. (Muscolino \& Cipriani, 2004).

Centro: conhecido como Power House é considerado o núcleo do corpo, ponto principal do método. (Muscolino \& Cipriani, 2004).

Fluidez: Após desenvolver coordenação na realização dos movimentos se adquire um ritmo, com isso, é possível passar de um exercício para o outro sem nenhuma interrupção (Muscolino \& Cipriani, 2004).

\section{Aparelhos do pilates}

Os aparelhos mais utilizados no Pilates, segundo Da Luz et al. (2014), são: Chair, Reformer, Cadillac, Ladder Barriel e Wall Unit. (Figura 2)

Chair é um aparelho de dimensões pequenas, porém muito versátil e excelente para realizar o fortalecimento da parte central do corpo, possibilitando inúmeras alternativas para se trabalhar membros superiores e inferiores. 
Reformer é o mais completo dos aparelhos, além da versatilidade, oferecendo inúmeras alternativas para se trabalhar membros.

Ladder Barriel é o único aparelho que não se utiliza das molas, onde as repetições e cargas estão inter-relacionadas, utilizado para trabalhar a musculatura paravertebral, abdominais e para o alongamento.

Wall Unit é um aparelho que contém um par de molas, alça de mãos e pés, cinto de segurança, uma barra móvel, e dez pares de ganchos, onde quanto mais alto eles estiverem, maior será a intensidade.

Figura 2 - Aparelhagem desenvolvida por Joseph Pilates.

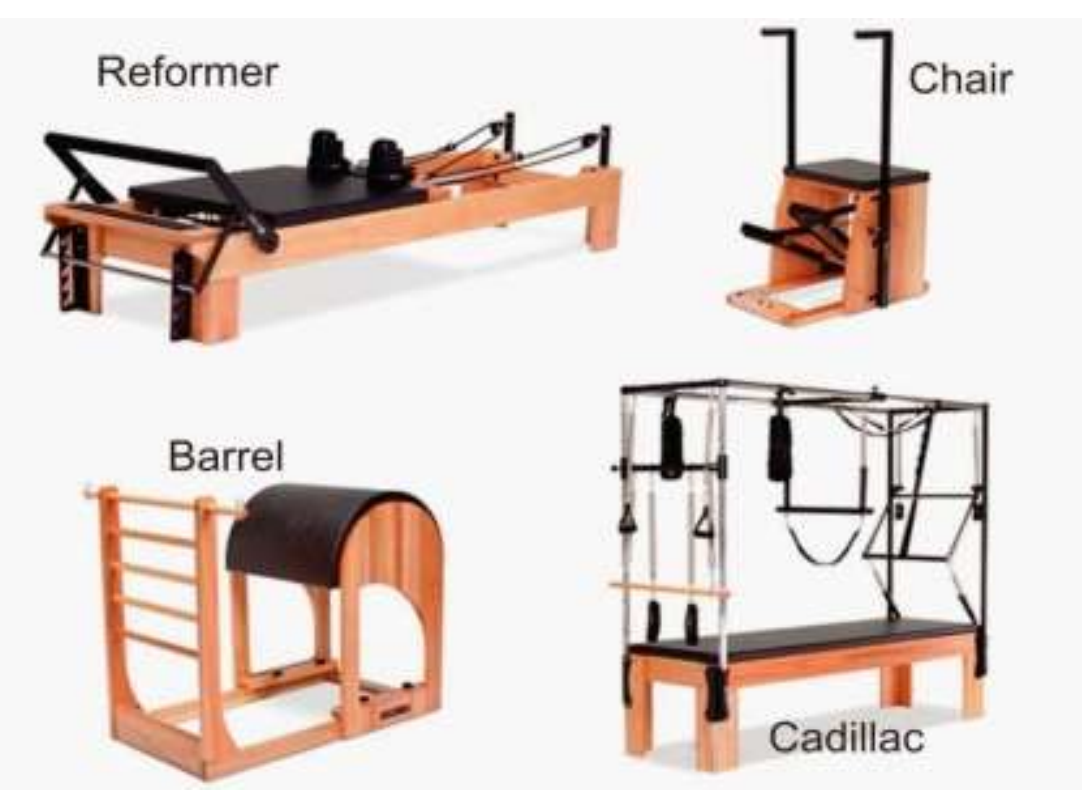

Fonte: https://br.pinterest.com/pin/434456695296587033/visual-search/?cropSource=6\&h=397\&w=530\&x=16\&y=12

\section{Eficiência dos exercícios de pilates}

Os exercícios possibilitam o desenvolvimento de variáveis fundamentais, como: a força, o equilíbrio e a flexibilidade, que reflete na qualidade de vida e na saúde física e emocional dos idosos, fazendo com que eles melhorem nas execuções de tarefas simples e básicas, além de melhorarem as habilidades articulares do corpo, que utilizam informações proprioceptivas, promovendo mais estabilidade (Comunello, 2011).

Em 2009, Silva e Mannrich, demonstraram que a realização dos exercícios de Pilates envolvem contrações isotônicas e isométricas, com ênfase no Power House (ou centro de força), gerando benefícios demonstrados na tabela 1, figura 3 e figura 4.

Tabela 1 - Benefícios adquiridos pela realização do método de Pilates.

Fortalecer a musculatura de modo global ou localizado;

Aumentar a flexibilidade geral;

Corrigir distúrbios posturais;

Melhorar equilíbrio estático e dinâmico;

Alongamento axial;

Estimulação proprioceptiva;

Promover o relaxamento muscular geral;

Fonte: Silva; Mannrich (2009) 
Figura 3 - Objetivos adquiridos com o desempenho do Pilates.

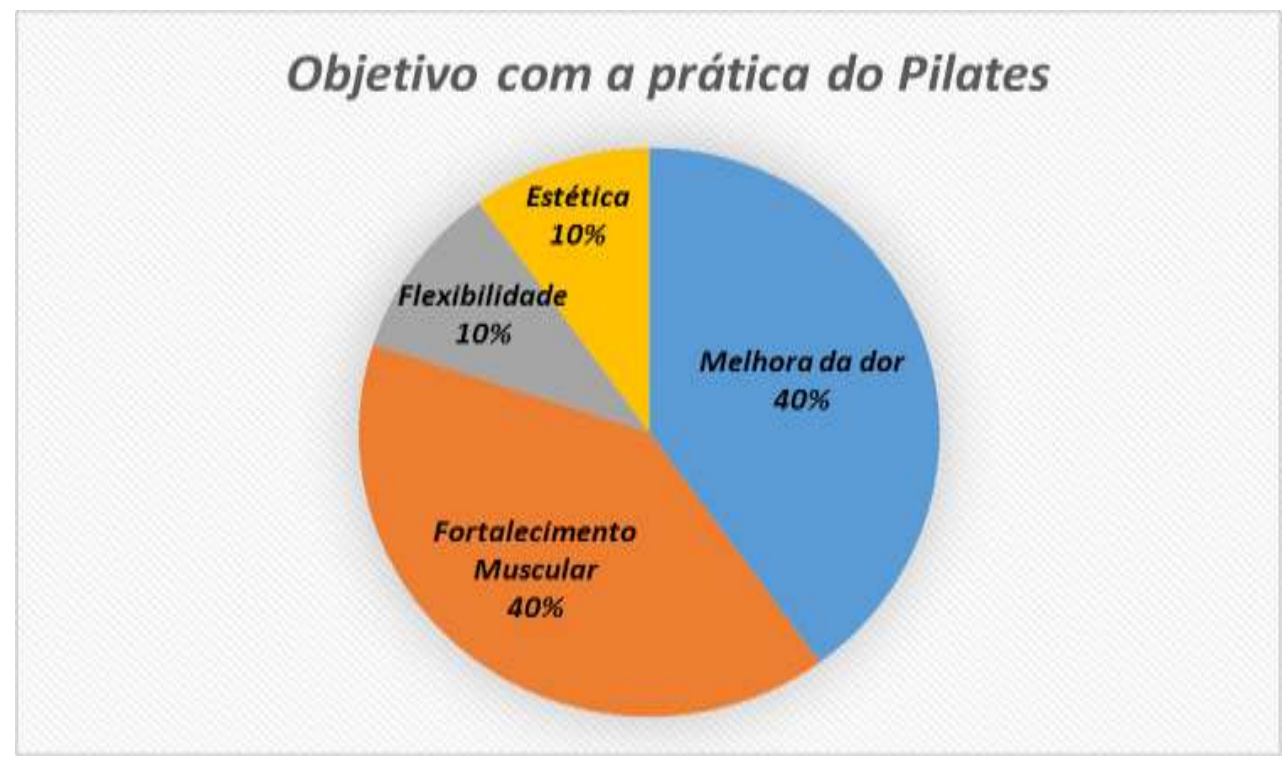

Fonte: https://interfisio.com.br/wp-content/uploads/2019/04/fig2.png

Figura 4 - Vantagens da aplicação do método Pilates em proveito da saúde

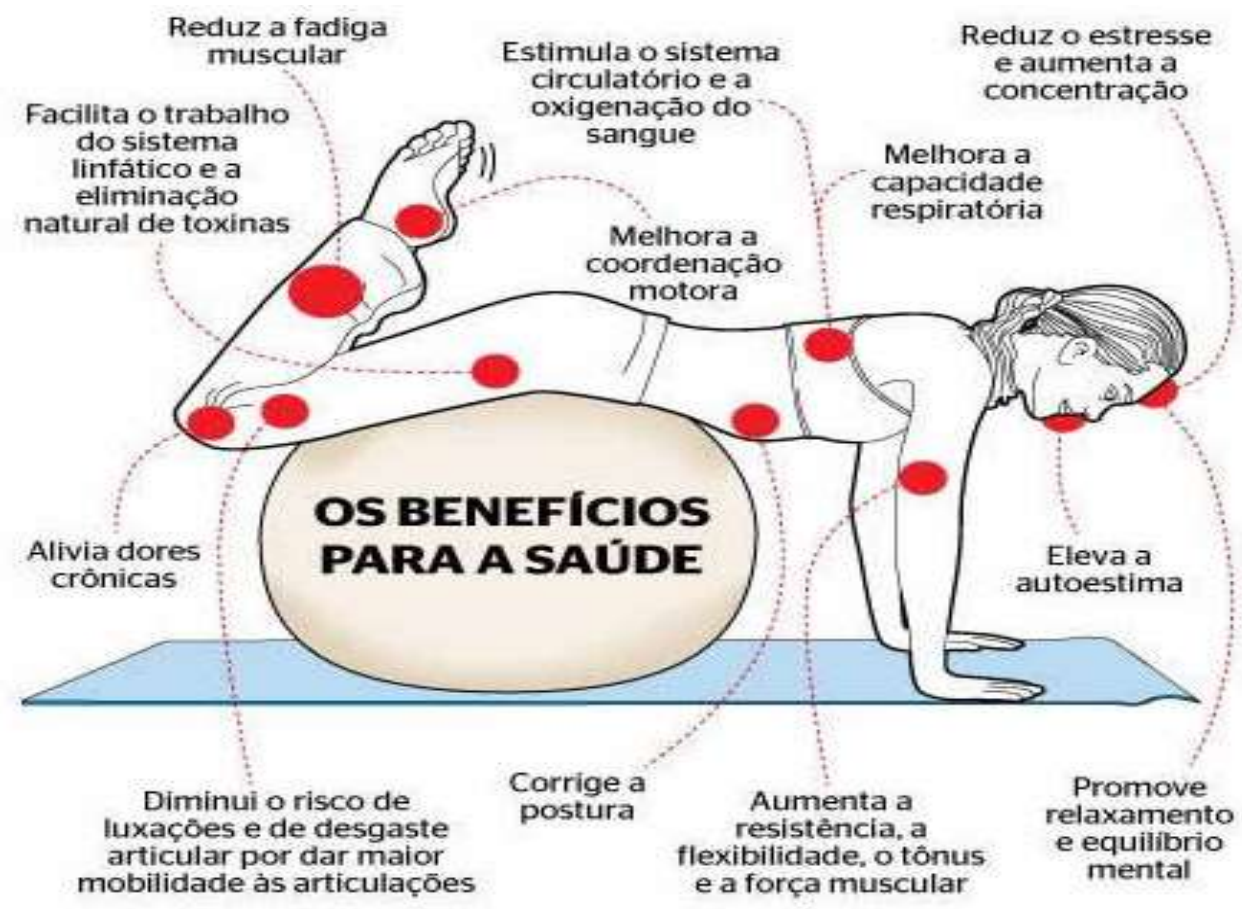

Fonte: https://belezaesaude.com/i/f/o/saude/conteudo/fitness/pilates-beneficios-1.jpg

A realização dos exercícios do método Pilates para a terceira idade é iniciada com as posições básicas, que irão sendo dificultadas e modificadas de acordo com o condicionamento, com as limitações e os objetivos a serem alcançados com os idosos, podendo ser adequados quando necessário, e de forma individual. A intensidade da realização dos exercícios do Pilates depende dos avanços que o idoso obteve nas sessões anteriores, além do objetivo a ser alcançado e a percepção do profissional, onde o nível de esforço e o peso de carga para os idosos durante as sessões devem ser iniciadas de maneira leve ou moderado, o que irá depender da avaliação feita pelo profissional (Miller, 2002; Butler, 1998). 
O método se embasa nos conceitos de cinesiologia e fisiologia, trabalhando alongamentos associados com a respiração e exercícios resistidos, é por isso que os princípios do Pilates devem ser cobrados durante a execução dos movimentos para uma melhor eficácia em sua realização, e posteriormente, melhora da condição física deste idoso. Esses princípios básicos do Pilates, são: concentração, para que haja atenção ao realizar os exercícios; centralização, fortalecendo toda a musculatura que promove a sustentação da coluna; precisão, que ditará consciência e percepção ao movimento; respiração, proporcionando o aumento da força e melhora da capacidade respiratória; controle, proporcionando mais estabilidade, o equilíbrio, promovendo o alinhamento corporal e articular; fluidez, trabalhando a cognição, autoconfiança e a efetividade (Sacco et al, 2005; Muscolino; Cipriani, 2004a; Bertolla et al, 2007; Brunelli 2009).

\section{Benefícios do método pilates para os idosos}

O Pilates proporciona aos idosos um atendimento personalizado, por realizar um trabalho corporal direcionado e de acordo com as limitações físicas, de acordo com a idade. São muitos os benefícios que o Pilates oferece aos idosos: diminuição da dor, principalmente as lombares, melhor percepção dos movimentos, aumento do fortalecimento muscular, da flexibilidade e do equilíbrio, entre outros (Gallagher \& Kryzanowska, 2000).

Através dos princípios básicos, o método Pilates atua amenizando os distúrbios da capacidade funcional, proporcionadas pelo envelhecimento e pelas patologias adquiridas, como a senescência, possibilitando assim o melhoramento cardiorrespiratório, o ciclo de marcha, além de trabalhar a sobrecarga, o aumento da resistência, da flexibilidade, do equilíbrio postural, da propriocepção, o auxílio a manutenção da pressão arterial, melhora a circulação sanguínea, o condicionamento físico, a estabilidade, proporcionando independência, reduzindo o número de quedas, e mais autoconfiança, conseguindo melhorar também a coordenação motora e a consciência corporal pela eficiência da realização dos exercícios que fortalecem a musculatura estabilizadora da coluna, e influencia na calcificação óssea. Nitidamente, o método melhora a mobilidade e a força, que é reduzida com o processo de envelhecimento e geralmente pelas patologias degenerativas (Hackbart 2015).

Diante disso, os exercícios do Pilates influenciam na manutenção da capacidade funcional dos idosos, e influenciam também na qualidade de vida, o que gera um impacto positivo na autoestima e na autonomia dos idosos, e que é percebida no desempenho da realização das atividades diárias. Durante os últimos anos, o Pilates vem ganhando destaque por ser uma opção de exercício físico para os idosos, pois através do trabalho resistido e com exercícios de alongamento dinâmico, atua no fortalecimento muscular, sendo as principais características do método, oferecendo uma melhor percepção dos movimentos e contribui com o equilíbrio corporal, possibilitando o alívio do estresse e possibilitando a qualidade de vida (Comunello, 2011).

O método Pilates engloba tanto o condicionamento mental, quanto físico. As atuais 500 variações de movimentos que podem ser executadas, se deram a partir de 34 movimentos do método original, podendo estes serem realizados com ou sem a utilização dos aparelhos, onde podem ser adaptadas às condições físicas de cada idoso e as suas devidas necessidades. Benefícios esses que ajudam na prevenção de lesões, proporcionam o alívio de dores, diminuem os desequilíbrios musculares, por se tratar de um método que não demanda desgaste articular e o número de repetições reduzidos e realizados com exatidão tratam e/ou previnem algumas patologias principalmente, as ocupacionais (Rodrigues, 2010).

\section{Considerações Finais}

O envelhecimento é um processo fisiológico, que desenvolve alterações que ocorrem comumente no corpo, envolvendo alterações degenerativas. Constata-se que o método Pilates é uma ferramenta de grande eficácia para os fisioterapeutas, para manter, ou melhorar as capacidades funcionais da terceira idade, dando ênfase de acordo com seus princípios, onde a prática do método apresenta benefícios emocionais e físicos, por ser de caráter suave e leve, oferecendo 
relaxamento mental e adotando uma maior consciência corporal, promovendo melhora no equilíbrio, na postura, ganhando mais força muscular e alongamento muscular. Tudo, por meio de princípios que são usados na execução dos exercícios, onde se trazem benefícios circulatórios, musculoesqueléticos, respiratórios, posturais e emocionais. Dessa forma, o tema abordado possui relevância pois demonstra que o método Pilates propõe uma melhora na qualidade de vida da terceira idade como um todo, alterando seu estado emocional e físico.

\section{Referências}

Bear, M. F., Commors, B. W., \& Paradiso, M. A. (2002) Neurociências: desvendando o sistema nervoso. (2a ed.), Artes Médicas; 856 p.

Bertolla, F; Baroni, B. M.; Junior, E. C. P. L \& Oltramari, J. D. (2007) Efeito de um programa de treinamento utilizando o método Pilates® na flexibilidade de atletas juvenis de futsal. Revista Brasileira de Medicina do Esporte. 13(4).

Brunelli, Ane R. (2009) Os efeitos do método Pilates no equilíbrio e na marcha de pacientes com acidente vascular encefálico (AVE). Monografia apresentada a Universidade do Extremo Sul Catarinense, UNESC, 2009.

Butler, R. N.; Davis, R. \& Lewis, C. B. (1998) Physical fitness: exercise prescription for older adults: part 3 of a roundtable discussion. Geriatrics, 53(11), 4554.

Carvalho, E.M.S, et al. (2011) A postura do idoso e suas implicações clínicas. Revista Geriatria \& Gerontologia, 4-170.

Chaudhary, K. R., El-Sikhry, H., \& Seubert, J. M. (2011) Mitochondria and the aging heart. J Geriatr Cardiol. 8(3):159-67.

Clarke B. Normal bone anatomy and physiology. Clin J Am Soc Nephrol. 3(Suppl. 3):S131-9.

Comunello, J. F. (2011) Benefícios do método Pilates e sua aplicação na reabilitação. Instituto Salus.

Da Luz, M. A., Costa, L. O., Fuhro, F. F., Manzoni, A. C., Oliveira, N. T. \& Cabral. C. M. (2014) Effectiveness of Mat Pilates or Equipment-Based Pilates Exercises in Patients With Chronic Nonspecific Low Back Pain: A Randomized Controlled Trial. Physical Therapy. 94, 623-631.

Davies, M. R. Muscle. In: Davies, A., Blakeley, A. G. H., Kidd, C. Human Physiology. Elsevier; 2001.

Gallagher, S. P., \& Kryzanowska R. (2000) O método pilates, de condicionamento bísico. Competition; 2000.

Gasparotto, L, P, R et al. (200) Autoavaliação da postura por idosos com e sem hipercifose torácica. Ciência \& Saúde Coletiva. 717-722.

Hackbart, C. R. (2015) Método Pilates: um fenômeno processual? The journal of the latin American sociocultural studies of sports. 6(2), 44-54,

Hain, T. C., Ramaswamy, T. S., \& Hillman, M. A. (2012) Anatomia e Fisiologia do Sistema Vestibular Normal. In: Herdman SJ. Reabilitação Vestibular. (2a ed.), Editora Manole.

Horak, F. B. (2006) Postural orientation and equilibrium: what do we need to know about neural control of balance to prevent falls? Age Ageing. 2006;35(S2):7-11.

Juliano, R. A. \& Bernardes, R. (2014) A teoria do método pilates: Da história à biomecânica. 36-41.

Lopes, M. A.; \& Siedler, M. J. (2007) Atividade Física: agente de transformação dos idosos. Texto \& Contexto - A Enfermagem e o Envelhecer Humano.

Marques. D. (2012) Análise da capacidade funcional de mulheres idosas praticante do método Pilates. Fisioterapia em Movimento, $25(2)$, 445- 451.

Martins, R. A. (2013) Método Pilates: Histórico, benefícios e aplicações: revisão sistemática da literatura. Monografia (Especialização em Pilates) Universidade Católica de Goiás, Goiânia, 2013.

Matsudo, S. M. M. (2001) Envelhecimento e atividade física. Midiograf, 2001.

Miller, A. M. \& Iris, M. (2002) Health promotion attitudes ad strategies in olds adults. Health education \& behavior, $29(2), 249-67$.

Miranda, L. B. \& Morais, P. D. C. (2009) Efeito do método pilates sobre a composição corporal e flexibilidade. Revista Brasileira de Prescrição e Fisiologia do Exercício. 3(13), 16-21.

Muscolino, J. \& Caprimini, S. (2004) “Pilates and Powerhouse” II. Jounal of Bodywork Movement Therapies. 8:15-24,2004.

Naveh-Benjamin M, Cowan N, Kilb A \& Chen Z. Age-related differences in immediate serial recall: dissociating chunk formation and capacity. Mem Cognit. 35(4):724-37.

Neto, M, S. (2004) Presença de Fraquezas e Encurtamentos Musculares em Secretárias com Dor no Segmento Lombar da Coluna Vertebral. Revista PIBIC, 1. 81-91.

Panelli, C. \& Marco A. (2016) Método Pilates de condicionamento do corpo: um programa para toda vida. 
Research, Society and Development, v. 10, n. 12, e244101220355, 2021

(CC BY 4.0) | ISSN 2525-3409 | DOI: http://dx.doi.org/10.33448/rsd-v10i12.20355

Pereira, A. S. et al. (2018). Metodologia da pesquisa científica. UFSM

Ralston, S. H. (2010) Genetics of osteoporosis. Ann NY Acad Sci. 1192:181-9.

Rodrigues, B. G. S., Cader, A. S., Torres, N. V. O. B., Oliveira, E. M., \& Dantas, E. H. M. (2005) Autonomia funcional de idosas praticantes de Pilates. FisioterPesqui. 17(4):300-5.

Sacco, I. C. N. et al. (2005) "Método Pilates em revista: aspectos biomecânicos de movimentos específicos para reestruturação postural - Estudos de caso". $R$. bras. Ci e Mov.

Schwertner, D. S. (2007) Avaliação postural em Idosos: Metodologia e Diagnóstico. Revista Saúde Pública, 21(3), $211-224$.

Sherwood L. (2010) Human Physiology: from cells to systems. (7th ed.), USA: Brooks/Cole Eds.; c2010. Chapter 8, Muscle physiology; $257-64$.

Siler B. (2008) O corpo pilates: um guia para fortalecimento, alongamento e tonificação sem o uso de máquinas. Summus Editorial.

Silva, T. C. L. G.; \& Mannrich, G. (2009) Pilates na Reabilitação: uma revisão sistemática. Revista Fisioterapia em Movimento. 22(3), 449-455.

Sung, C. H., \& Chuang, J. Z. (2010) The cell biology of vision. J Cell Biol. 190(6):953-63.

Trevisol, F.C. \& Silva, S. (2009). Aula inicial de pilates promove efeito agudo na flexibilidade da musculatura isquiotibial. Revista Brasileira de Prescrição e Fisiologia do Exercício, 3(14), 161-170.

Verderi, E. (2002) Educação postural e qualidade de vida. Lecturas Educácion Física y deportes. Revista digital. 